Article

\title{
Integrated Analysis of Transcriptomic and Metabolomic Data Reveals the Mechanism by Which LED Light Irradiation Extends the Postharvest Quality of Pak-choi (Brassica campestris L. ssp. chinensis (L.) Makino var. communis Tsen et Lee)
}

\author{
Zhicheng Yan ${ }^{1,+}{ }^{+}$Jinhua Zuo ${ }^{1,+}{ }^{\oplus}$, Fuhui Zhou ${ }^{1,2}$, Junyan Shi ${ }^{1}$, Dongying $\mathrm{Xu}^{2}$, Wenzhong Hu ${ }^{2}$, \\ Aili Jiang ${ }^{2}$, Yao Liu ${ }^{1}$ and Qing Wang ${ }^{1, *}$ \\ 1 Key Laboratory of the Vegetable Postharvest Treatment of Ministry of Agriculture, Beijing Key Laboratory of \\ Fruits and Vegetable Storage and Processing, Key Laboratory of Biology and Genetic Improvement of \\ Horticultural Crops (North China) of Ministry of Agriculture, Key Laboratory of Urban Agriculture (North) \\ of Ministry of Agriculture, National Engineering Research Center for Vegetables, Beijing Academy of \\ Agriculture and Forestry Sciences, Beijing 100097, China; 18840821461@163.com (Z.Y.); \\ zuojinhua@126.com (J.Z.); zhoufuhuihui@126.com (F.Z.); shijunyan0130@126.com (J.S.); \\ happyyaoyaoer@126.com (Y.L.) \\ 2 Laboratory of Biotechnology and Bioresources Utilizatio, Ministry of Education, College of Life Science, \\ Dalian Minzu University, Dalian 116600, China; 18840875773@163.com (D.X.); hwz@dlnu.edu.cn (W.H.); \\ jal@dlnu.edu.cn (A.J.) \\ * Correspondence: wangqing@nercv.org; Tel.: +86-10-51503058 \\ + These authors contributed equally to this work.
}

Received: 21 October 2019; Accepted: 30 January 2020; Published: 7 February 2020

\begin{abstract}
Low-intensity $\left(10 \mu \mathrm{mol} \mathrm{m}^{-2} \mathrm{~s}^{-1}\right)$ white LED (light-emitting diode) light effectively delayed senescence and maintained the quality of postharvest pakchoi during storage at $20^{\circ} \mathrm{C}$. To investigate the mechanism of LED treatment in maintaining the quality of pakchoi, metabolite profiles reported previously were complemented by transcriptomic profiling to provide greater information. A total of 7761 differentially expressed genes (DEGs) were identified in response to the LED irradiation of pak-choi during postharvest storage. Several pathways were markedly induced by LED irradiation, with photosynthesis being the most notable. More specifically, porphyrin and chlorophyll metabolism and glucosinolate biosynthesis were significantly induced by LED irradiation, which is consistent with metabolomics reported previously. Additionally, chlorophyllide a, chlorophyll, as well as total glucosinolate content was positively induced by LED irradiation. Overall, LED irradiation delayed the senescence of postharvest pak-choi mainly by activating photosynthesis, inducting glucosinolate biosynthesis, and inhibiting the down-regulation of porphyrin and chlorophyll metabolism pathways. The present study provides new insights into the effect and the underlying mechanism of LED irradiation on delaying the senescence of pak-choi. LED irradiation represents a useful approach for extending the shelf life of pak-choi.
\end{abstract}

Keywords: Pak-choi; LED irradiation; RNA-seq; metabolomics; postharvest quality

\section{Introduction}

Pak-choi (Brassica campestris L. ssp. Chinensis) is a cruciferous vegetable native to China. Currently, pak-choi has also become more popular and widely used in Western diets [1]. Pak-choi contains high levels of several nutrients that are beneficial to human health, including ascorbic acid, glucosinolates, 
and polyphenols [2,3]. A high level of consumption of cruciferous vegetables has been related with a reduced risk of lung and colorectal cancer [4] and epidemiological studies have provided evidence that the consumption of cruciferous vegetables more effectively protects against cancer than the total intake of mixed fruits and vegetables [5]. Pak-choi, however, suffers from several postharvest problems that affect its sensory and nutritional quality, including weight loss, wilting, and leaf yellowing. Thus, several approaches have been explored to maintain the postharvest quality of pak-choi, such as the application of aqueous chlorine dioxide combined with ultraviolet-C irradiation [6], and low temperature storage [7]. Greater efforts are needed, however, to identify a cost-effective, reliable approach to extending the postharvest quality of harvested produce.

Light is one of the most important environmental variables affecting the concentrations of phytochemicals in plants [8]. In this regard, the use of light emitting-diodes (LED) represents an efficient and economical approach to administer light treatments to vegetables because of their small size, safety, stability, and cold light illuminator $[9,10]$. The use of LED lighting for the postharvest treatment of many different vegetables has been reported. Exposure to white-blue LED light delayed the senescence of harvested broccoli [11], red LED light suppressed the postharvest yellowing of broccoli and reduced the loss of ascorbic acid [12], LED White light, red light irradiation can improve the nutrition and flavor quality of post-harvest citrus [13], and LED light treatment can induce the ripening of bananas and improve their quality and nutrition potential [14]. Thus, it appears that LED irradiation may have broad applications for the postharvest preservation of vegetables. Additional research is required, however, to determine the mechanism by which LED light exposure maintains the postharvest quality of vegetables in order to optimize its use.

Our previous study demonstrated that $10 \mu \mathrm{mol} \mathrm{m}^{-2} \mathrm{~s}^{-1}$ white LED light irradiation maintained the quality, increased the antioxidant capacity, and regulated the chlorophyll metabolism of postharvest pakchoi [15]. Additionally, we used an untargeted metabolomic approach to investigate the effect of LED irradiation on the metabolite profile of pak-choi, the data denoted that LED irradiation kept the quality of pak-choi by regulating several metabolic processes, elevating folate, thiamine, glutathione, riboflavin, and total carotenoid content, decreasing the degradation of glucosinolate, and enhancing key synthetic precursors of chlorophyll [16].

Transcriptomic and metabolomic analyses are useful approaches for identifying gene-to-metabolite networks involved in the physiological responses of plants $[17,18]$. The integration of differentially-expressed gene profiles with metabolite data is an effective way to better understand gene-to-metabolite networks [19], the function of differentially-expressed genes [20], and to integrate biological information and broaden our knowledge of plant metabolism [21]. The integrated use of transcriptomics and metabolomics has been used to investigate the metabolic changes that occur during the postharvest storage of produce. For example, Ding et al. [22] identified a network of processes that occur during the postharvest senescence process in citrus fruits. Thus, in the present study, we augmented transcriptomic profiling and performed a joint analysis with previous metabolomics to improve understanding of the response of harvested pak-choi to LED irradiation.

\section{Material and Methods}

\subsection{Plant Material and LED Treatment}

Sample treatment and LED parameter was as previously described [15]. Pak-choi (Brassica campestris L. ssp. Chinensis) plants were harvested in Xiaotangshang, Beijing (China) at their optimum harvest date and immediately transported to the laboratory. Undamaged pak-choi plants with thick, fleshy, firm stalks and glossy, dark-green leaves with no evidence of mechanical damage were selected to study. The selected plants were then randomized and partitioned into two groups, with each group containing approximately $2 \mathrm{~kg}$ of plants. Subsequently, each harvested pakchoi plant was placed in a polyethylene bag $(0.03 \mathrm{~mm})$ and stored at $20 \pm 1{ }^{\circ} \mathrm{C}$ at approximately $90 \%$ relative humidity. The control group was stored under dark conditions, while the LED-treated group was stored under 
continuous irradiation with white LED light at wavelengths of $448 \mathrm{~nm}$ and $549 \mathrm{~nm}$ at a light intensity of approximately $10 \mu \mathrm{mol} \mathrm{m} \mathrm{m}^{-2} \mathrm{~s}^{-1}$. Other parameters of white LED light were red $(600-700 \mathrm{~nm})$ at $22.221 \mu \mathrm{mol} \mathrm{m} \mathrm{m}^{-2} \mathrm{~s}^{-1}$, green (500-599 $\mathrm{nm}$ ) at $43.325 \mu \mathrm{mol} \mathrm{m}^{-2} \mathrm{~s}^{-1}$, blue (400-499 $\mathrm{nm}$ ) at $25.461 \mu \mathrm{mol}$ $\mathrm{m}^{-2} \mathrm{~s}^{-1}$, far-red $(701-780 \mathrm{~nm})$ at $2.3373 \mu \mathrm{mol} \mathrm{m} \mathrm{m}^{-2} \mathrm{~s}^{-1}$, and PPF $(400-700 \mathrm{~nm})$ at $91.0 \mu \mathrm{mol} \mathrm{m}^{-2} \mathrm{~s}^{-1}$. The red/far-red ratio was 9.51 and the red/blue ratio was 0.73 . The light intensity was measured using a Lighting Passport (ALP-01, Asensetek, Taiwan). Approximately $250 \mathrm{~g}$ of pak-choi were collected from each group on each sample day and mixed to obtain a homogeneous sample. The liquid nitrogen was used to freeze the collected material, and stored the collected material at $-80{ }^{\circ} \mathrm{C}$ until subsequent analysis. Our previous study indicated that pak-choi stored in the dark (control) conditions exhibited a significant decrease in quality after $5 \mathrm{~d}$. Therefore, three biological replicates were collected just prior to treatment (T01, T02, T03), and three biological replicates of pak-choi stored in the dark (T04, T05, T06) or under LED lights (T07, T08, T09) were collected at $5 \mathrm{~d}$ and subjected to transcriptomic analyse.

\subsection{RNA-Seq Library Preparation and Sequencing}

The RNA-seq library preparation and sequencing were determined using the method depicted by [23]. RNA concentration was measured using NanoDrop 2000 (Thermo Fisher Scientific, Waltham, MA, USA). RNA integrity was assessed using the RNA Nano 6000 Assay Kit of the Agilent Bioanalyzer 2100 system (Agilent Technologies, Santa Clara, CA, USA). A total amount of $1 \mu \mathrm{g}$ RNA per sample was used as input material for the RNA sample preparations. Sequencing libraries were generated using NEBNext UltraTM RNA Library Prep Kit for Illumina (NEB, Ipswich, MA, USA) following the manufacturer's recommendations and index codes were added to attribute sequences to each sample.

\subsection{Transcriptome Data Analysis}

\subsubsection{Quality Control}

Raw data (raw reads) of fastq format were firstly processed through in-house perl scripts. In this step, clean data (clean reads) were obtained by removing reads containing adapter, reads containing ploy-N and low-quality reads from raw data. At the same time, Q20, Q30, GC-content and sequence duplication level of the clean data were calculated. All the downstream analyses were based on clean data with high quality.

\subsubsection{Comparative Analysis}

The adaptor sequences and low-quality sequence reads were removed from the data sets. Raw sequences were transformed into clean reads after data processing. These clean reads were then mapped to the reference genome sequence. Only reads with a perfect match or one mismatch were further analyzed and annotated based on the reference genome. Hisat2 tools soft were used to map with reference genome.

\subsubsection{Functional Annotation of Genes}

Genes were identified and annotated using the following databases: $\mathrm{Nr}$ (ftp://ftp.ncbi.nih.gov/blast/ db/FASTA/); Pfam (http://pfam.xfam.org/); KOG/COG (http://www.ncbi.nlm.nih.gov/KOG); Swiss-Prot (http://www.uniprot.org/); KEGG (http://www.genome.jp/kegg/); and GO (http://www.geneontology. org/).

\subsubsection{Quantification of Gene Expression Levels}

Gene expression levels were estimated using fragments per kilobase of transcript per million fragments mapped (FPKM) based on the following formula:

$$
\mathrm{FPKM}=\frac{\mathrm{cDNA} \text { Fragments }}{\text { Mapped Fragments (Millions) } \times \text { Transcript Length }(\mathrm{kb})}
$$




\subsubsection{Differential Expression Analysis}

Differential expression analysis of two conditions/groups was performed using the DESeq $\mathrm{R}$ package (1.10.1, http://www.bioconductor.org/packages/release/bioc/html/DESeq.html). DESeq [24] provides statistical routines for determining differential expression in gene expression data using a model based on the negative binomial distribution. Expression values were adjusted to control the false discovery rate as described by [25]. Differences in the expression of genes having an adjusted $p$-value $<0.05$ were designated as differentially expressed genes (DEGs). The FDR (false discovery rate) was adjusted by PPDE (posterior probability of being DE). The threshold for significantly differential expression was set as FDR $<0.01 \& \mid \log 2$ (foldchange) $\mid \geq 2$.

\subsection{Sample Preparation and Metabolomic Analysis}

Sample preparation and the assay procedure used followed previous experiments $[16,26]$.

\subsection{Transcriptome and Metabolome Coalition Analysis}

Coalition of KEGG pathway enrichment of DEGs and differentially expressed metabolites was conducted using data on differentially expressed genes and metabolites that were enriched in the same pathway as determined by the KEGG analysis.

\subsubsection{Correlation Analysis}

Pearson correlation coefficients (PCC) and P-values were calculated separately between $\log _{2}$ (genes) and $\log _{2}$ (metabolites). Genes and metabolites were selected following the standards of PCC $>0.8$ and $p$-value $<0.05$.

\subsubsection{Correlation Network Visualization}

A network model was constructed to illustrate the relationship between genes and metabolites. Genes and metabolites enriched in the same pathways and with correlation coefficients greater than 0.8 were selected for use in the model.

\subsubsection{Canonical Correlation Analysis}

Canonical correlation analysis (CCA) was used to explore the relationships between differentially-expressed genes and metabolites that were in the same KEGG enriched pathways. CCA was used to identify linear combinations between the two variables and identify maximum correlations.

\subsection{Glucosinolates}

Total glucosinolate content was determined by the method depicted by [27]. Frozen pak-choi tissue powder $(0.05 \mathrm{~g})$ was blended with $2.8 \mathrm{~mL}$ of a solution of methanol-acetic acid ( $40 \%$ methanol and $0.5 \%$ acetic acid; avoiding total glucosinolate hydrolysis by endogenous myrosinase), and another equivalent of it was added to $2.8 \mathrm{~mL}$ deionized water (blank). The two mixtures were incubated at $37^{\circ} \mathrm{C}$ for $15 \mathrm{~min}$, adding $2.1 \mathrm{~mL}$ methanol and $3 \mathrm{mg}$ of activated carbon to each sample to stop the reaction. The samples were centrifuged twice at $12,000 \times \mathrm{g}$ for $15 \mathrm{~min}$ at $4{ }^{\circ} \mathrm{C}$. One $\mathrm{mL}$ of the supernatant was then added to a $4 \mathrm{~mL}$ standard glucose solution and incubated at $37^{\circ} \mathrm{C}$ for $30 \mathrm{~min}$. Adding $4 \mathrm{~mL}$ $\mathrm{H}_{2} \mathrm{SO}_{4}$ to end the reaction, measured at $540 \mathrm{~nm}$ of absorbance. The content of glucose in the reaction solution was the standard to compute the content of total glucosinolate.

\subsection{Chlorophyll}

Chlorophyll content was determined using a modified version of the method reported by [28]. Pak-choi tissue powder $(1 \mathrm{~g})$ was homogenized in $10 \mathrm{~mL}$ acetone: ethanol (2:1), then the mixture was centrifuged at $12,000 \times \mathrm{g}$ for $10 \mathrm{~min}$ at $4{ }^{\circ} \mathrm{C}$. The total chlorophyll content was determined by measuring sample absorbance at $645 \mathrm{~nm}$ and $663 \mathrm{~nm}$. 


\subsection{Chlorophyllide a}

Pak-choi tissue $(0.5 \mathrm{~g})$ was extracted with $9 \mathrm{~mL}$ phosphate buffer $(50 \mathrm{mM}, \mathrm{pH} 7.4)$ and the mixture was then centrifuged at $13,000 \times g$ at $4{ }^{\circ} \mathrm{C}$ for $15 \mathrm{~min}$. The supernatant was then collected. Chlorophyllide a content was determined using an ELISA Kit (LMAI Bio, Shanghai, China) at $450 \mathrm{~nm}$ with a microplate reader (Multiskan GO, Thermo Scientific, Waltham, MA, USA) according to the manufacturer's protocol. Standard was used to generate a standard curve under the same condition, and chlorophyllide a content was calculated based on the standard curve.

\subsection{Statistical Analyses}

All statistical were analyzed by SPSS 19.0 (SPSS Inc., Chicago, IL, USA). The one-way ANOVA was used on data, and means were compared by LSD test at a significance level of $p<0.05$.

\section{Results and Discussion}

\subsection{Transcriptome Response and Joint Analysis}

A transcriptomic (Supplementary Tables S1 and S2) was conducted and analyzed in conjunction with previous metabolomic [16] of pak-choi during storage to characterize the regulatory mechanism underlying the white-light LED delay of senescence. The three groups were Initial (prior to treatment), CK $5 \mathrm{~d}$ (pak-choi stored in the dark for $5 \mathrm{~d}$ ) and LED $5 \mathrm{~d}$ (pak-choi irradiated with LED lights for $5 \mathrm{~d}$ ). The correlation among the three sample-types was analyzed. The correlation analysis (Figure 1A) indicated a clear separation between the three groups of samples, demonstrating that the irradiation of pak-choi with LED white light alters gene expression. A total of 7761 DEGs [|log2(foldchange) $\mid \geq 2$ $(F C \geq 2)$ ] (Supplementary Table S2); false discovery rate $\leq 0.01$ (FDR $\leq 0.01$ )] were identified between the three sample types (Initial, CK 5 d, and LED 5 d). This included 6692 DEGs (2733 up- and 3959 down-regulated) in the Initial/CK 5 d comparison, 3906 DEGs (1572 up- and 2334 down-regulated) in the Initial/LED $5 \mathrm{~d}$ comparison, and 1339 DEGs (1011 up and 328 down-regulated) in the CK $5 \mathrm{~d} /$ LED $5 \mathrm{~d}$ comparison (Figure 1B), A Venn diagram (Figure 1C) illustrates the distribution of DEGs among the three treatment groups. 


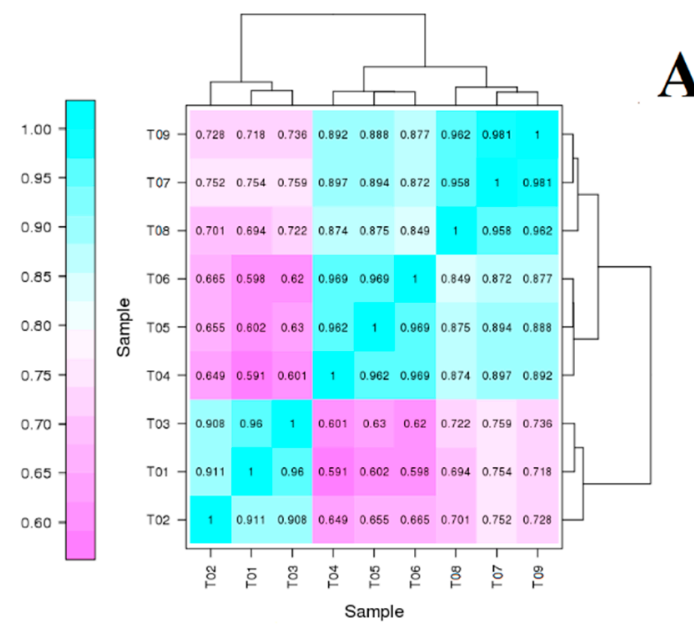

A

B
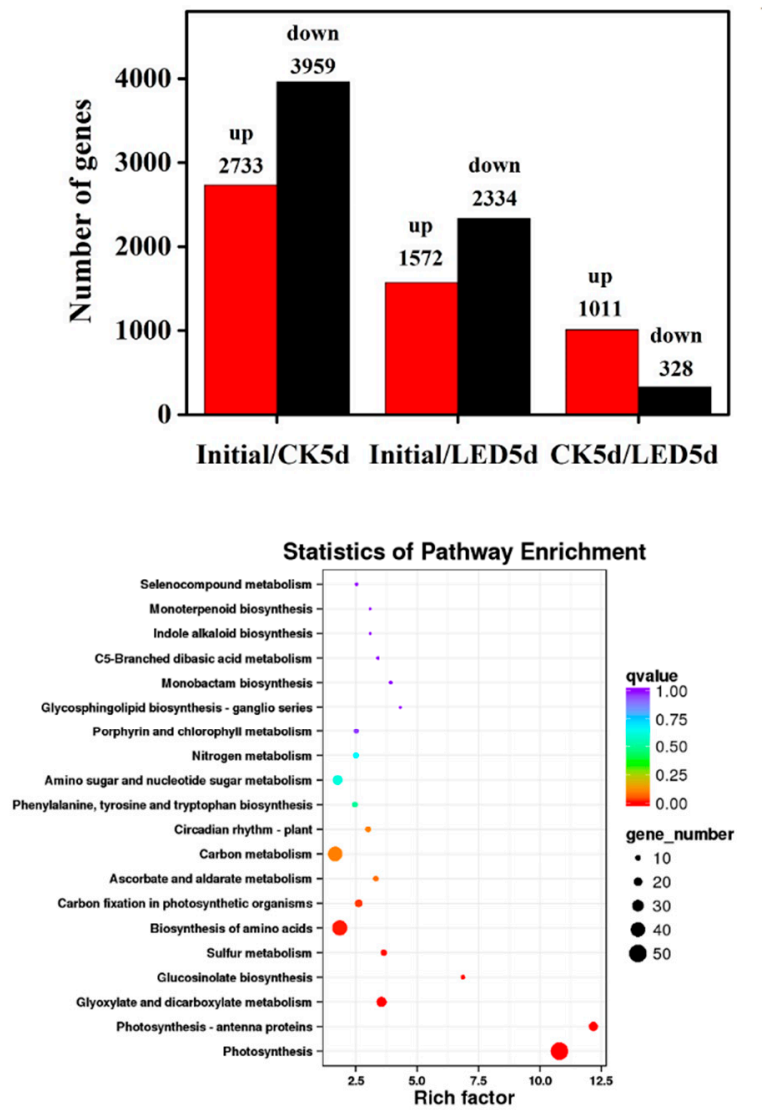

Figure 1. Expression and correlation analysis between pak-choi treatment groups. (A) Initial (T01, T02, T03), dark-stored (control) for $5 \mathrm{~d}$ (T04, T05, T06), and LED-irradiated for $5 \mathrm{~d}$ (T07, T08, T09). (B) The number of differentially expressed genes (DEGs) ( $\mid \log 2$ (foldchange) $\mid \geq 2$ (FC $\geq 2)$; false discovery rate $\leq$ $0.01($ FDR $\leq 0.01)$ ). (C) Venn diagram of DEGs (0d/CK5d, initial/dark-stored 5d; 0d/LED5d, initial/LED 5 d; CK5d/LED5d, dark-stored 5d/LED 5 d). (D) KEGG pathway enrichment analysis of DEGs.

Relative to the Initial/LED $5 \mathrm{~d}$ comparison, twice as many DEGs were identified in the Initial/CK $5 \mathrm{~d}$ comparison (Figure 1B). This indicates that the white LED light treatment inhibited many of the changes in gene expression that occurred during the postharvest storage of pak-choi under dark conditions. A heat map of gene expression (Supplementary Table S3; Supplementary Figure S1) indicated that expression of most of the genes in the LED samples were down-regulated relative to the initial samples and only a few of genes were up-regulated. In most cases, the level of gene expression in the LED-treatment samples was between the CK $5 \mathrm{~d}$ (dark-stored) and initial samples, and more similar to the expression levels in the initial samples. This indicates that white LED light treatment inhibited many of the senescence-related changes in gene expression that happen in pak-choi during dark storage. The data indicate that the use of a white LED treatment may be an effective way to maintain the quality of pak-choi during storage by inhibiting senescence-related gene expression. LED irradiation has been shown to keep the quality of several vegetable crops after harvest. Ma et al. [12] reported the reduced loss of ascorbic acid (AsA) by exposure to white LED light was highly regulated at the transcriptional level. Hasperué et al. [11] demonstrated that continuous white-blue LED light can delay the senescence of broccoli after harvest. JoaquÃn et al. [29] reported that LED light can extend the postharvest quality of brussels sprouts during storage.

Kyoto Encyclopedia of Genes and Genomes (KEGG) enrichment analysis revealed that many metabolic-, amino acid-, and enzyme activity-related pathways were affected by the LED white light treatment (Figure 1D). Photosynthesis was the most obviously impacted. Previous metabolomic 
data indicated that porphyrin and chlorophyll metabolism and glucosinolate biosynthesis were stimulated by LED irradiation [16]. In this study, these two pathways were also identified by KEGG enrichment analysis. Thus, three representative pathways were selected for further analysis including photosynthesis, porphyrin and chlorophyll metabolism, and glucosinolate biosynthesis.

\subsection{Photosynthesis}

Photosynthesis involves two processes: light reactions that produce ATP and NADPH, and light-independent carbon reactions that fix atmospheric $\mathrm{CO}_{2}$ into organic molecules using the generated ATP and NADPH [30]. Transcriptome analysis indicated that the LED white light treatment significantly affected the light reactions (PLR) of photosynthesis (Figure 2A). Maintaining PLR would have a positive effect on pak-choi quality during postharvest storage because the availability of greater levels of photoassimilates could delay senescence [31]. Braidot et al. [32] reported that a light treatment of lamb's lettuce activated photosynthesis and the maintenance of PLR promoted the production of ATP. A higher energy status can delay senescence [33], as ATP is involved in anti-oxidative processes [34]. Our transcriptomic data indicated that 49 genes (Supplementary Table S4) related to PLR were among the DEGs $(F C \geq 2$; FDR $\leq 0.01)$ in the LED treatment samples. The identified genes were related with Photosystem II, Photosystem I, Cytochrome b6f complex, photosynthethic electron transport, and F-type ATPase in PLR. A contrast of the expression profiles of all the treatment sample types indicated that, relative to dark-stored (control) and LED treatment samples, the initial samples had the supreme extent of PLR-related gene expression. In contrast, all of the PLR-related genes exhibited down-regulation after storage for 5 days in both the dark-stored (control) and LED treatment samples. Compared to the dark-stored (control) samples, however, the extent of down-regulation was obviously less in the LED treatment samples (Figure 2B), indicating that that LED treatment helped to maintain PLR-related gene expression in pak-choi during storage. These results indicate that the expression of PLR-associated genes was activated or at least partially maintained in pak-choi during postharvest storage by the white LED light treatment. A similar result was obtained by Hasperué et al. [29] using LED light to maintain photosynthetic activity, the green color and extend the shelf life of brussels sprouts. Braidot et al. [32] also improved the quality of lamb's lettuce during storage with the use of low-intensity lighting. 


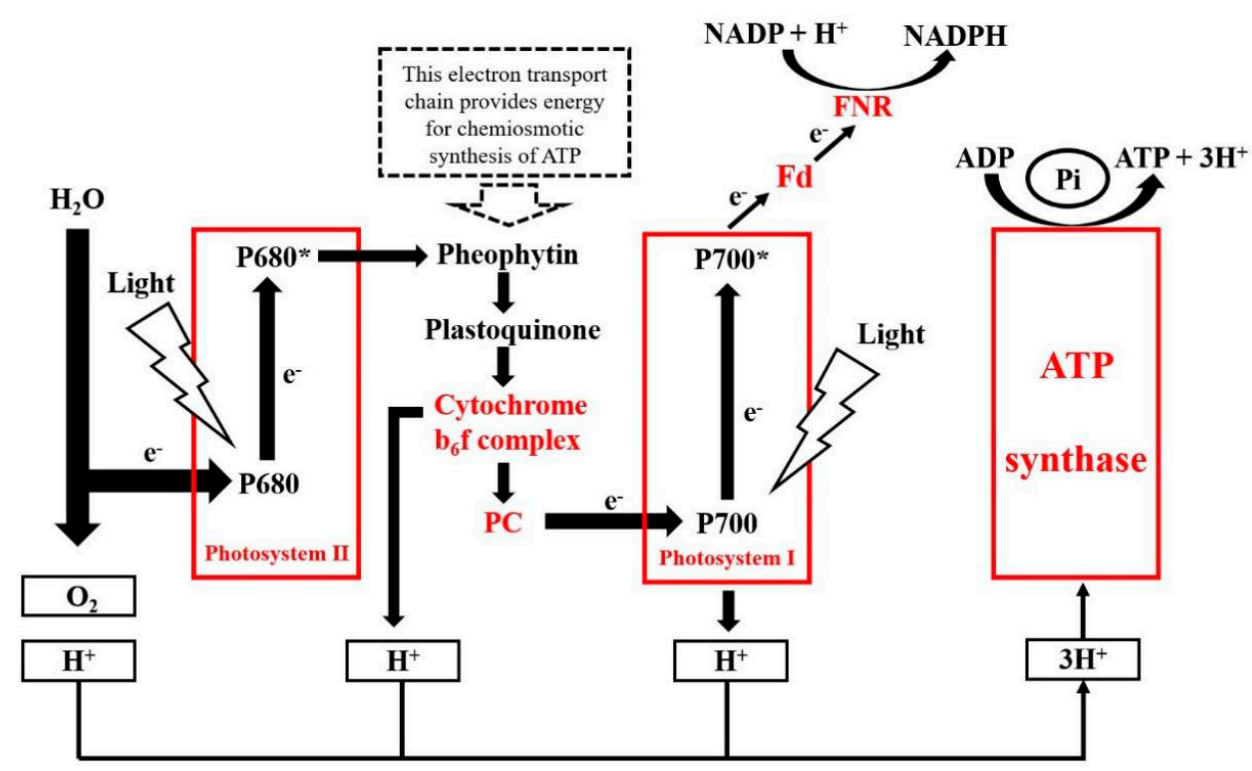

A

Photosynthethic electron transport

PC: Plastocyanin, Fd: Ferredoxin, FNR: Ferredoxin--NADP ${ }^{+}$reductase

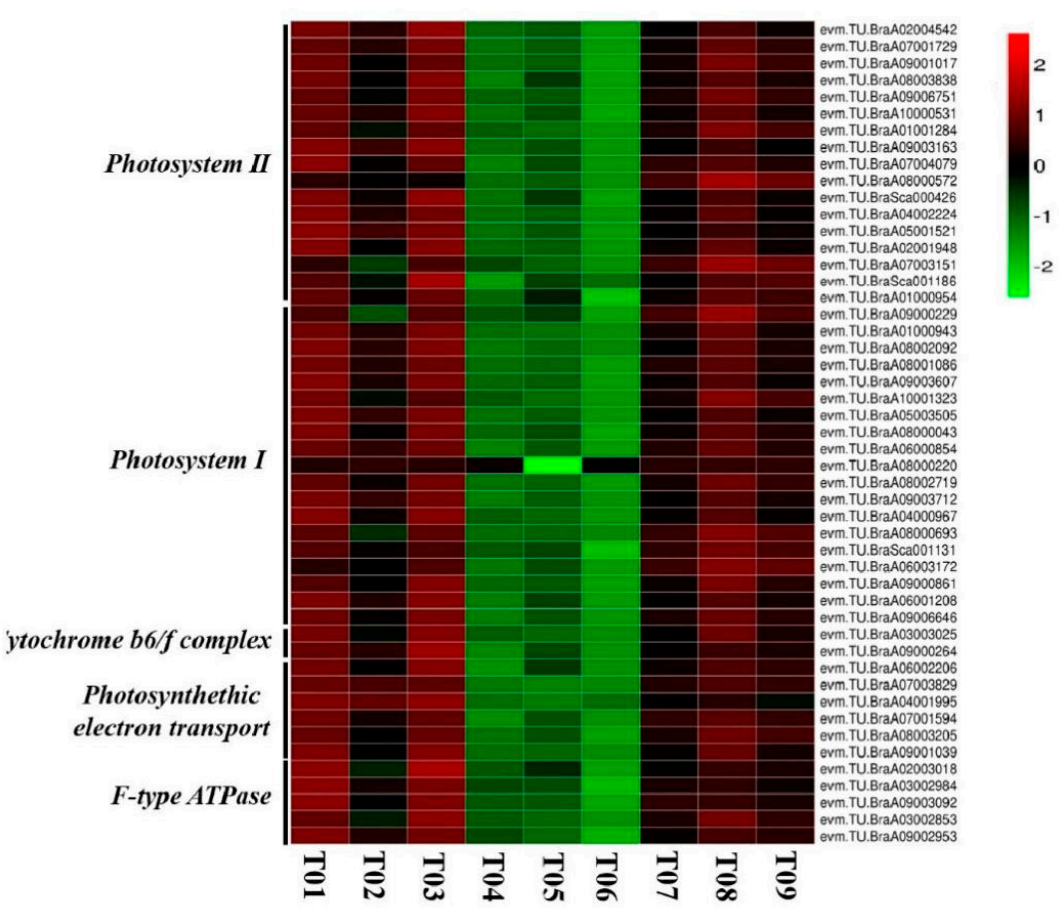

Figure 2. The effect of LED irradiation on the expression of genes involved in photosynthesis in pak-choi. (A) Metabolites or genes expressed at a higher level in the LED treatment group, relative to the dark-stored (control) treatment-group, are illustrated in red. Metabolites or genes expressed at a lower level in the LED treatment group, relative to the dark-stored (control) treatment group, are illustrated in green. (B) Expression pattern of genes involved in photosynthesis in response to LED irradiation. A total of 49 DEGs (FC $\geq 2$; FDR $\leq 0.01$ ) associated with photosynthesis were identified. Log2-based FPKM values were used to generate the heat map. The scale represents the relative signal intensity of FPKM values (T01, T02, T03: initial; T04, T05, T06: dark-stored control 5d; T07, T08, T09: LED $5 \mathrm{~d})$. 


\subsection{Chlorophyll Synthesis}

Green color, resulting from high levels of chlorophyll, is a quality parameter strongly desired by consumers as it reflects freshness. Chlorophyll degradation occurs rapidly during postharvest storage of pak-choi, reflected as a yellowing of the produce, and is one of the most obvious indicators of senescence. Therefore, maintaining chlorophyll levels in pak-choi is a direct way to preserve sensory quality. Light, as the important environmental factors for plants [12], is widely-used to keep the postharvest quality of vegetables. Braidot et al. [32] reported that low intensity light treatment of lamb's lamb's lettuce (Valerianella olitoria [L.] Pollich) during postharvest storage resulted in higher levels of chlorophyll. Büchert et al. [35] demonstrated that light could effectively maintain the postharvest chlorophyll content of broccoli by inhibiting BoPPH expression (a chlorophyll-degradation gene), and Jin et al. [36] indicated that a green LED light treatment maintained chlorophyll levels in harvested broccoli florets. In this study, KEGG enrichment analysis revealed that the white LED light treatment had a significant positive effect on porphyrin and chlorophyll metabolism pathways (Figure 3A). Two factors related to chlorophyll synthesis are present in porphyrin and chlorophyll metabolism pathways: the composite of chlorophyll precursors and the constitution of chlorophyll a/b. The synthesis of chlorophyll precursors from L-glutamic acid to protoporphyrin IX is catalyzed by a series of enzymes [37]. In the present study, six genes (Supplementary Table S5) related to chlorophyll synthesis were among the DEGs $(F C \geq 2$; FDR $\leq 0.01)$ in this experiment. The expression of two genes related to the key enzyme, HemA, were differentially expressed in the three sample groups of pak-choi. Heat map analysis revealed that the initial samples had the highest level of expression of the HemA-related genes, and that after five days of storage the expression of these genes was up-regulated in the LED treatment group relative to the dark-stored (control) treatment group (Figure 3B). These results indicate that the expression of HemA-related genes was down-regulated in the dark-stored (control) samples and that the white LED light treatment could delay the down-regulation of these genes. As HemA catalyzes the formation of L-Glutamate 1-semialdehyde from L-Glutamyl-tRNA [38], the up-regulated expression of HemA-related genes was positive to the composite of chlorophyll precursors. Regarding the synthesis of chlorophyll $a / b$, significantly differences (FC $\geq 2$; FDR $\leq 0.01$ ) were observed in the expression of genes encoding three enzymes (chlI, chlE, and por) and the level of two metabolites (divinylchlorophyllide a, chlorophyllide a) [16]. The enzymes chlI, chlE, and por play an important role in catalyzing the synthesis of chlorophyll [39], as divinyl chlorophyllide a and chlorophyllide a are major components of chlorophyll synthesis [40]. In the current study, genes encoding chlI, chlE, and por were again highest in the initial sample group. However, the LED treatment helped to maintain the expression level of these genes relative to the dark-stored (control) sample group. These data indicate chlI, chlE, and por gene expression are down-regulated during the senescence of pak-choi but that the LED treatment delayed their down-regulation. The metabolomic analysis revealed a high level of divinyl chlorophyllide a and chlorophyllide a in the initial sample group and that the level of these metabolites significantly decreased in the dark-stored treatment group after five days of storage. In contrast, the levels of these metabolites were maintained in the LED treatment group of pak-choi after five days of storage [16]. Overall, the results of this study indicated that the LED treatment inhibited the decrease in chlorophyll levels that occurs in pak-choi during dark storage by maintaining the expression of genes encoding the enzymes (HemA, chll, chlE, por) and the levels of major substrates (divinyl chlorophyllide a and chlorophyllide a) of chlorophyll biosynthesis. This finding was validated by determining chlorophyllide a and chlorophyll levels in the various treatment groups utilized in the current study (Figure 3C,D). 

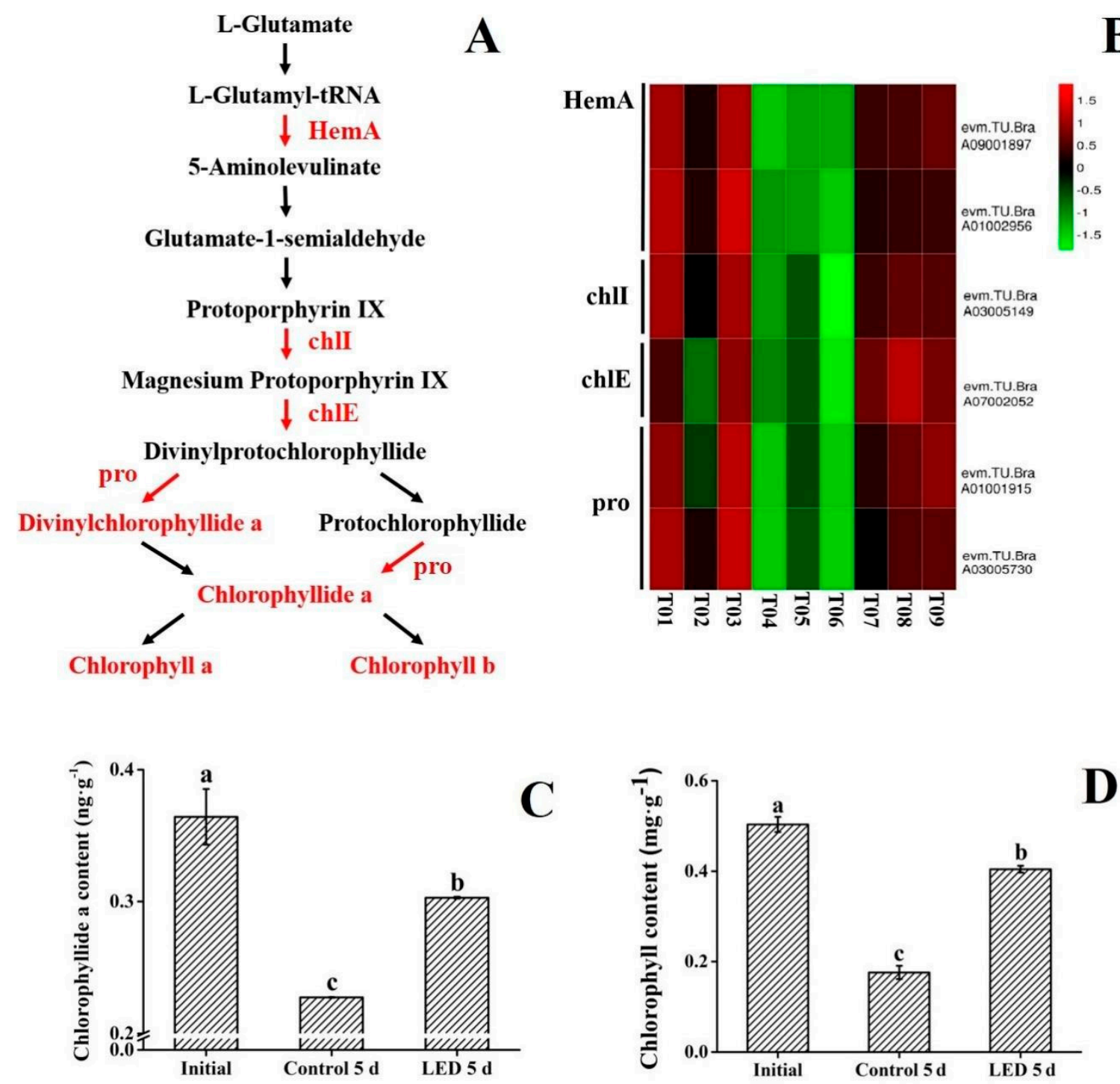

Figure 3. The effect of LED irradiation on the expression of genes involved in the chlorophyll synthesis and chlorophyll and chlorophyllide a content in pak-choi. (A) Metabolites or genes expressed at a higher level in the LED treatment group, relative to the dark-stored (control) treatment group, are illustrated in red. Metabolites or genes expressed at a lower level in the LED treatment group, relative to the dark-stored (control) treatment group, are illustrated in green. (B) Expression pattern of genes involved in the porphyrin and chlorophyll metabolism pathways in response to LED irradiation. Six DEGs $(F C \geq 2 ; F D R \leq 0.01)$ associated with photosynthesis were identified. Log2 based FPKM values were used to create the heat map. The scale represents the relative signal intensity of FPKM values (T01, T02, T03: initial; T04, T05, T06: dark-stored control 5d; T07, T08, T09: LED 5 d). (C,D) Levels of chlorophyllide a (C) and chlorophyll (D) in the three treatment groups (initial, dark-stored control 5d, and LED treatment $5 \mathrm{~d})$. Vertical bars represent the standard error of the mean $(n=3)$. Means denoted by the same letter do not differ significantly at $p<0.05$ as determined by LSD's multiple range test.

\subsection{Glucosinolate Biosynthesis}

Glucosinolate belongs to a class of secondary sulphur-containing metabolites produced by crucifers [41]. The major glucosinolate biosynthetic precursors are the amino acids, methionine, tryptophan and phenylalanine, that are used to produce aliphatic, indolic, and aromatic glucosinolates, respectively [42] (Figure 4A). Glucosinolates have been reported to function as against pathogen and deterrent action against insects [43]. Mithen et al. [44] reported that glucosinolates were toxic 
to Leptosphaeria maculans, and Mari et al. [45] observed that glucosinolates inhibited the conidial germination of postharvest pathogens of fruit. Glucosinolates and their metabolites were proved that effective reduce the risk of cancer in humans [46]. More specifically, Steinbrecher et al. [47] indicated that glucosinolates play a protective role against prostate cancer development possibly through the induction of biotransformation enzymes. In this study, the effect of LED treatment of pak-choi on the regulation of glucosinolate biosynthesis was investigated. Transcriptomic data identified seven DEGS (FC $\geq 2$; FDR $\leq$ 0.01) (Supplementary Table S6) related to glucosinolate biosynthesis in LED-treated pak-choi. The identified genes were related to six key enzymes in the biosynthesis of glucosinolate, including MAM1, CYP79F1, CYP83A1, CYP83B1, SUR1, UGT74B1. MAM1, CYP79F1, CYP83A1 are in the methionine pathway, CYP83B1 is in the chorismite pathway, and SUR1 and UGT74B1 are present in two different pathways. A decline in the level of all of the identified DEGs related to glucosinolate synthesis was observed in the dark-stored (control) treatment group after $5 \mathrm{~d}$ of storage. In contrast, 3 DEGS related to MAM1 and CYP79F1 were higher in the LED treatment group after $5 \mathrm{~d}$ of storage, relative to the dark-stored (control) sample group, and 4 DEGS related to CYP83A1, CYP83B1, SUR1, and UGT74B1, were higher than in the initial and dark-stored (control) treatment groups (Figure 4B). This indicates that the LED treatment up-regulated the expression genes related to these enzymes.
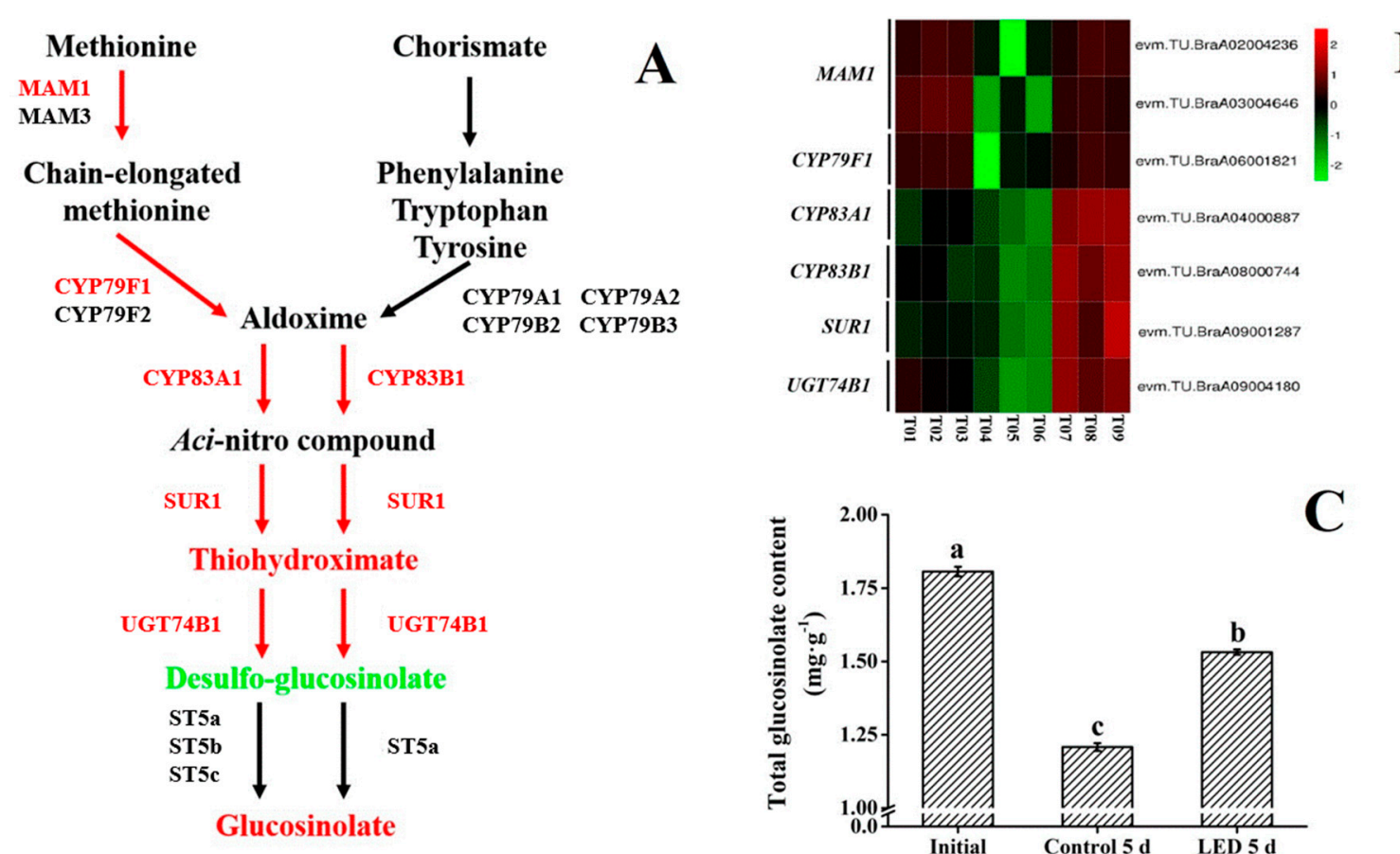

B

Figure 4. The effect of LED irradiation on the expression of genes in pak-choi involved in the biosynthesis of glucosinolate and levels of total glucosinolate. (A) Metabolites or genes expressed at a higher level in the LED treatment group, relative to the dark-stored (control) treatment group, are illustrated in red. Metabolites or genes expressed at a lower level in the LED treatment group, relative to the dark-stored (control) treatment group, are illustrated in green. (B) Expression pattern of genes involved in glucosinolate biosynthesis in response to LED irradiation. Seven DEGs (FC $\geq 2 ;$ FDR $\leq 0.01$ ) associated with photosynthesis were identified. Log2 based FPKM value were used to generate the heat map. The scale represents the relative signal intensity of FPKM values (T01, T02, T03: initial; T04, T05, T06: dark-stored control 5d; T07, T08, T09: LED treatment 5d). (C) Level of total glucosinolate in pak-choi in the three treatment groups (initial, dark-stored control 5d, and LED treatment $5 \mathrm{~d}$ ) of pak-choi. Vertical bars represent the standard error of the mean $(n=3)$. Means denoted by the same letter do not differ significantly at $p<0.05$ as determined by LSD's multiple range test.

Metabolomic data indicated that levels of S-(Indolylmethylthiohydroximoyl)-L-cysteine (SLC) and glucoiberverin in the LED treatment group were higher than in the other two treatment groups, but 
that the level of indolylmethyl-desulfoglucosinolate (ID) was lower [16]. SLC, ID and glucoiberverin play an important role in glucosinolate biosynthesis. SLC is a type of thiohydroximate, ID is a major substrate for the synthesis of indolylmethyl-glucosinolate [48], and glucoiberverin is an aliphatic glucosinolate. The higher levels of SLC and glucoiberverin and lower levels of ID in LED-treated pak-choi indicates that glucosinolate biosynthesis in pak-choi was induced by LED irradiation. Overall, LED treatment promoted glucosinolate biosynthesis and increased the level of glucosinolate in pak-choi (Figure 4C). An increase in glucosinolate levels in microgreens and baby, leafy-green brassica crops by LED light has been previously reported [49].

\section{Conclusions}

The present study indicated that the effect of LED irradiation on delaying senescence in pak-choi is related to the activation of photosynthesis, the induction of glucosinolate biosynthesis, and an inhibition of the down-regulation of porphyrin and chlorophyll metabolism pathways (Figure 5). White LED light treatment helped to up-regulate the expression of genes related to photosynthesis, maintain chlorophyll synthesis, and glucosinolate biosynthesis. Photosynthesis provided the energy needed to support ATP synthesis, while the maintenance of chlorophyll levels delayed the loss in sensory quality that typically occurs during the storage of pak-choi. The maintenance or increase in glucosinolate biosynthesis provided additional microbial and insect resistance and added nutritional value of pak-choi. All of the above contributed to the maintenance of the postharvest quality of pak-choi during storage. The application of LED light technology could be used to extend the shelf-life and improve the postharvest quality of pak-choi.

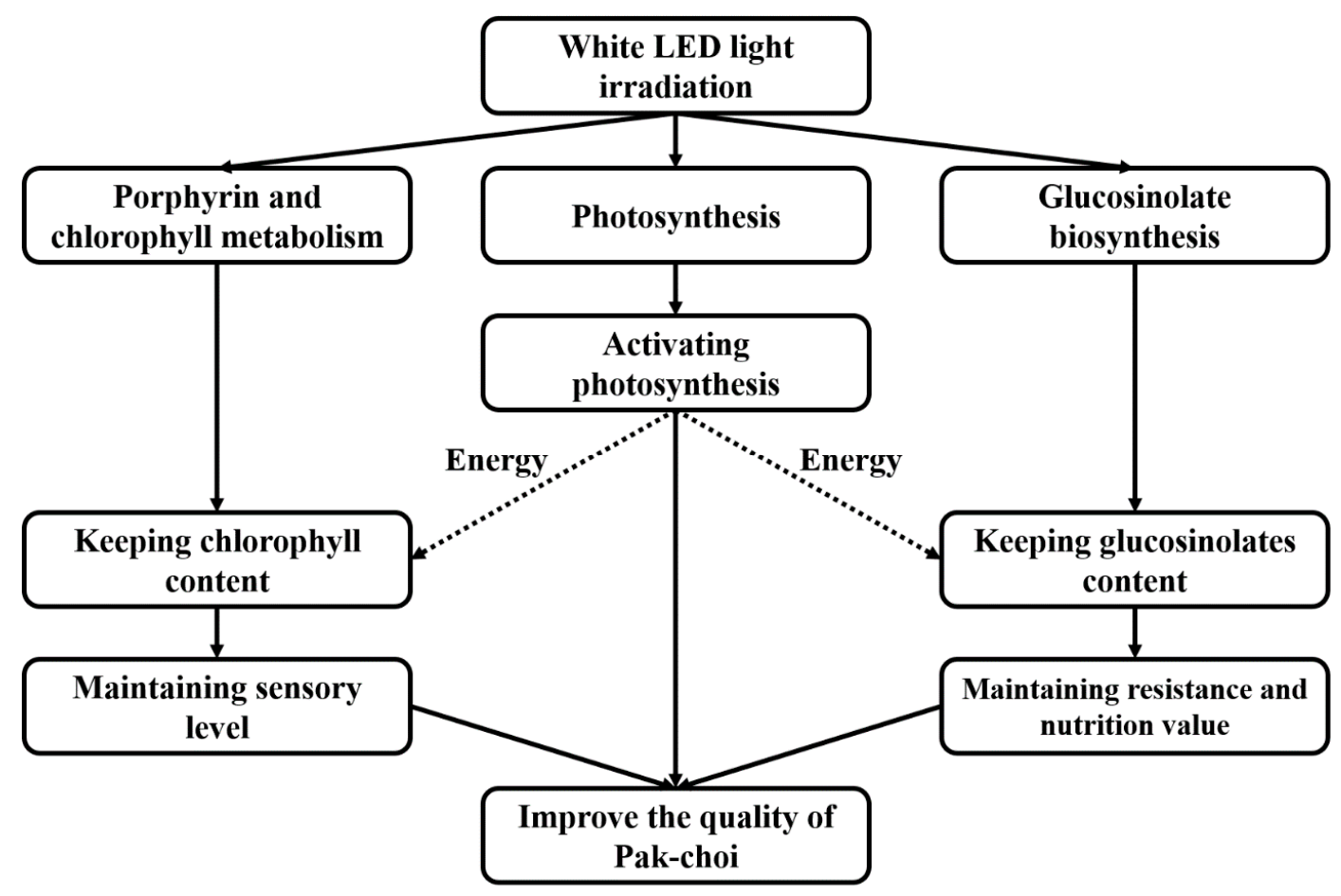

Figure 5. Diagrammatic model of the proposed mechanism responsible for the effect of LED irradiation on the maintenance of postharvest quality of pak-choi. White LED light treatment induces photosynthesis, chlorophyll synthesis, and glucosinolate biosynthesis. Photosynthesis provides the energy needed for ATP synthesis. The maintenance of chlorophyll synthesis during storage maintained the postharvest sensory quality of pak-choi. Increased levels of glucosinolate synthesis increased the level of microbial and insect resistance, as well as the nutritional value of pak-choi. Maintenance or increased levels of the above components extended and improved the postharvest quality of pak-choi during storage. 
Supplementary Materials: The following are available online at http://www.mdpi.com/2218-273X/10/2/252/s1, Figure S1: The heatmap of differentially expressed genes identified in dark-stored control 5d (T04, T05, T06), LED treatment 5d (T07, T08, T09) (FC $\geq 2$; FDR $\leq$ 0.01). Table S1: Known genes identified in pak-choi.; Table S2: The differentially expressed genes identified in initial (T01, T02, T03), dark-stored control 5d (T04, T05, T06), LED treatment $5 \mathrm{~d}(\mathrm{~T} 07, \mathrm{~T} 08, \mathrm{~T} 09)(\mathrm{FC} \geq 2 ; \mathrm{FDR} \leq 0.01)$; Table S3: The differentially expressed genes identified in dark-stored control 5d (T04, T05, T06), LED treatment 5d (T07, T08, T09) (FC $\geq 2$; FDR $\leq 0.01)$; Table S4: Target genes of the nat-siRNAs involved in Photosynthesis; Table S5: Target genes of the nat-siRNAs involved in porphyrin and chlorophyll metabolism; Table S6: Target genes of the nat-siRNAs involved in Glucosinolate biosynthesis.

Author Contributions: Data curation, Z.Y., J.Z., F.Z., J.S., D.X., W.H., A.J., Y.L., and Q.W.; Formal analysis, Z.Y., J.Z., F.Z., J.S., D.X., W.H., A.J., Y.L., and Q.W.; Methodology, J.Z.; Writing—original draft, Z.Y.; Writing-review \& editing, Z.Y., and F.Z. All authors have read and agreed to the published version of the manuscript.

Funding: This work was supported by the China Agriculture Research System Project (CARS-23), Beijing Municipal Science and Technology Commission (Z191100008619004), Collaborative innovation center of Beijing Academy of Agricultural and Forestry Sciences (KJCX201915), Key Laboratory of Biotechnology and Bioresources Utilization, Ministry of Education (KF2018002), the National Natural Science Foundation of China (31772022), the Natural Science Foundation of Beijing (6182016), Special innovation ability construction fund of Beijing Academy of Agricultural and Forestry Sciences (20180404 and 20180705).

Acknowledgments: The authors are thankful to the critical reading of the manuscript by Michael Wisniewski, USDA-ARS-Appalachian Fruit Research Station, and technical assistance by Biomarker Technologies Corporation.

Conflicts of Interest: The authors declare no conflict of interest.

\section{References}

1. Qiu, Y.; Li, X.X.; Zhi, H.Y.; Shen, D.; Lu, P. Differential expression of salt tolerance related genes in brassica campestris L. ssp. chinensis (L.) makino var. communis tsen et lee. J. Zhejiang Univ. Sci. B 2009, 10, 847-851. [CrossRef] [PubMed]

2. Lewis, J.; Fenwick, G.R. Glucosinolate content of brassica, vegetables: Analysis of twenty-four cultivars of calabrese (green sprouting broccoli, brassica oleracea, L. var. botrytis subvar. cymosa lam.). Food Chem. 1987, 25, 259-268. [CrossRef]

3. Rybarczyk-Plonska, A.; Hansen, M.K.; Wold, A.B.; Hagen, S.F.; Borge, G.I.A.; Bengtsson, G.B. Vitamin c in broccoli (brassica oleracea L. var. italica) flower buds as affected by postharvest light, UV-B irradiation and temperature. Postharvest Biol. Technol. 2014, 98, 82-89. [CrossRef]

4. Higdon, J.V.; Delage, B.; Williams, D.E.; Dashwood, R.H. Cruciferous vegetables and human cancer risk: Epidemiologic evidence and mechanistic basis. Pharmacol. Res. 2007, 55, 224-236. [CrossRef] [PubMed]

5. Keck, A.S.; Finley, J.W. Cruciferous vegetables: Cancer protective mechanisms of glucosinolate hydrolysis products and selenium. Integr. Cancer Ther. 2004, 3, 5-12. [CrossRef] [PubMed]

6. Kim, H.J.; Song, H.J.; Song, K.B. Effect of combined treatment of aqueous chlorine dioxide with ultraviolet-C on the quality of red chicory and pak choi during storage. J. Korean Soc. Food Sci. Nutr. 2011, 40, 245-252. [CrossRef]

7. Kramchote, S.; Srilaong, V.; Wongs-Aree, C.; Kanlayanarat, S. Low temperature storage maintains postharvest quality of cabbage (Brassica oleraceae var. capitata L.) in supply chain. Int. Food Res. J. 2012, 19, 759-763.

8. Samuolienè, G.; Sirtautas, R.; Brazaitytè, A.; Duchovskis, P. Led lighting and seasonality effects antioxidant properties of baby leaf lettuce. Food Chem. 2012, 134, 1494-1499. [CrossRef]

9. Morrow, R.C. LED lighting in horticulture. HortScience 2008, 43, 1947-1950. [CrossRef]

10. Bourget, C.M. An introduction to light-emitting diodes. Hortscience 2008, 43, 1944-1946. [CrossRef]

11. Hasperué, J.H.; Guardianelli, L.; Rodoni, L.M.; Chaves, A.R.; Martínez, G.A. Continuous white-blue led light exposition delays postharvest senescence of broccoli. LWT-Food Sci. Technol. 2015, 65, 495-502. [CrossRef]

12. Ma, G.; Zhang, L.; Setiawan, C.K.; Yamawaki, K.; Asai, T.; Nishikawa, F.; Nishikawab, F.; Maezawac, S.; Satod, H.; Kanemitsue, N.; et al. Effect of red and blue led light irradiation on ascorbate content and expression of genes related to ascorbate metabolism in postharvest broccoli. Postharvest Biol. Technol. 2014, 94, 97-103. [CrossRef]

13. Liu, S.; Hu, L.; Jiang, D.; Xi, W. Effect of Post-Harvest LED and UV Light Irradiation on the Accumulation of Flavonoids and Limonoids in the Segments of Newhall Navel Oranges (Citrus sinensis Osbeck). Molecules 2019, 24, 1755. [CrossRef] [PubMed] 
14. Huang, J.Y.; Xu, F.; Zhou, W. Effect of LED irradiation on the ripening and nutritional quality of postharvest banana fruit. J. Sci. Food Agric. 2018, 98, 5486-5493. [CrossRef] [PubMed]

15. Zhou, F.H.; Zuo, J.H.; Xu, D.Y.; Gao, L.P.; Wang, Q.; Jiang, A.L. Low intensity white light-emitting diodes (LED) application to delay senescence and maintain quality of postharvest pakchoi (Brassica campestris L. ssp. chinensis (L.) Makino var. communis Tsen et Lee). Sci. Hortic. 2020, 262, 109060. [CrossRef]

16. Zhou, F.H.; Zuo, J.H.; Gao, L.P.; Sui, Y.; Wang, Q.; Jiang, A.L.; Shi, J.Y. An untargeted metabolomic approach reveals significant postharvest alterations in vitamin metabolism in response to LED irradiation in pak-choi (Brassica campestris L. ssp. chinensis (L.) Makino var. communis Tsen et Lee). Metabolomics 2019, 15, 155. [CrossRef]

17. Sumner, L.W.; Mendes, P.; Dixon, R.A. Plant metabolomics: Large-scale phytochemistry in the functional genomics era. Phytochemistry 2003, 62, 817-836. [CrossRef]

18. Roessner, U.; Luedemann, A.; Brust, D.; Fiehn, O.; Linke, T.; Willmitzer, L.; Fernie, A. Metabolic profiling allows comprehensive phenotyping of genetically or environmentally modified plant systems. Plant Cell 2001, 13, 11-29. [CrossRef]

19. Goossens, A.; Hãkkinen, S.T.; Laakso, I.; Seppãnen-Laakso, T.; Biondi, S.; Sutter, V.; Lammertyn, F.; Nuutila, A.; Söderlund, H.; Zabeau, M.; et al. A functional genomics approach toward the understanding of secondary metabolism in plant cells. Proc. Natl. Acad. Sci. USA 2003, 100, 8595-8600. [CrossRef]

20. Hirai, M.Y.; Yano, M.; Goodenowe, D.B.; Kanaya, S.; Kimura, T.; Awazuhara, M.; Arita, M.; Fujiwara, T.; Saito, K. Integration of transcriptomics and metabolomics for understanding of global responses to nutritional stresses in arabidopsis thaliana. Proc. Natl. Acad. Sci. USA 2004, 101, 10205-10210. [CrossRef]

21. Hall, R.D. Plant metabolomics: From holistic hope, to hype, to hot topic. New Phytol. 2006, 169, $453-468$. [CrossRef] [PubMed]

22. Ding, Y.; Chang, J.; Ma, Q.; Chen, L.; Liu, S.; Jin, S.; Han, J.; Xu, R.; Zhu, A.; Gao, J.; et al. Network analysis of postharvest senescence process in citrus fruits revealed by transcriptomic and metabolomic profiling. Plant Physiol. 2015, 168, 357-376. [CrossRef] [PubMed]

23. Zuo, J.; Wang, Y.; Zhu, B.; Luo, Y.; Wang, Q.; Gao, L. Analysis of the coding and non-coding RNA transcriptomes in response to bell pepper chilling. Int. J. Mol. Sci. 2018, 19, 2001. [CrossRef] [PubMed]

24. Anders, S.; Huber, W. Differential expression analysis for sequence count data. Genome Biol. 2010, 11, R106.

25. Benjamini, Y.; Hochberg, Y. Controlling the false discovery rate: A practical and powerful approach to multiple testing. J. R. Stat. Soc, Ser. B 1995, 57, 289-300. [CrossRef]

26. Cajka, T.; Fiehn, O. Toward merging untargeted and targeted methods in mass spectrometry-based metabolomics and lipidomics. Anal. Chem. 2015, 88, 524-545. [CrossRef]

27. Hsu, F.C.; Wirtz, M.; Heppel, S.C.; Bogs, J.; Krämer, U.; Khan, M.S.; Bub, A.; Hell, R.; Rausch, T. Generation of Se-fortified broccoli as functional food: Impact of Se fertilization on S metabolism. Plant Cell Environ. 2011, 34, 192-207. [CrossRef]

28. Zhang, L.; Xiao, S.; Chen, Y.J.; Xu, H.; LI, Y.G.; Zhang, Y.W.; Luan, F.S. Ozone sensitivity of four pakchoi cultivars with different leaf colors: Physiological and biochemical mechanisms. Photosynthetica 2016, 55, 478-490. [CrossRef]

29. Hasperué, J.H.; Rodoni, L.M.; Guardianelli, L.M.; Chaves, A.R.; Martínez, G.A. Use of LED light for Brussels sprouts postharvest conservation. Sci. Hortic. 2016, 213, 281-286.

30. Tanai, C.; Shengxi, S.; Peter, J.N. Enhancing photosynthesis in plants: The light reactions. Essays Biochem. 2018, 62, 85-94.

31. Favre, N.; Bárcena, A.; Bahima, J.V.; Martínez, G.; Costa, L. Pulses of low intensity light as promising technology to delay postharvest senescence of broccoli. Postharvest Biol. Technol. 2018, 142, 107-114. [CrossRef]

32. Braidot, E.; Petrussa, E.; Peresson, C.; Patui, S.; Bertolini, A.; Tubarob, F.; Wählbyc, U.; Coanc, M.; Vianelloa, A.; Zancani, M. Low-intensity light cycles improve the quality of lamb's lettuce (Valerianella olitoria [L.] Pollich) during storage at low temperature. Postharvest Biol. Technol. 2014, 90, 15-23. [CrossRef]

33. Wang, H.; Qian, Z.; Ma, S.; Zhou, Y.; Patrick, J.W.; Duan, X.; Qu, H. Energy status of ripening and postharvest senescent fruit of litchi (Litchi chinensis Sonn.). BMC Plant Biol. 2013, 13, 1-16. [CrossRef] [PubMed]

34. Adyanthaya, I.; KWON, Y.I.; Apostolidis, E.; Shetty, K. Apple postharvest preservation is linked to phenolic content and superoxide dismutase activity. J. Food Biochem. 2009, 33, 535-556. [CrossRef] 
35. Büchert, A.M.; Civello, P.M.; Martínez, G.A. Effect of hot air, UV-C, white light and modified atmosphere treatments on expression of chlorophyll degrading genes in postharvest broccoli (Brassica oleracea L.) florets. Sci. Hortic. 2011, 127, 214-219. [CrossRef]

36. Jin, P.; Yao, D.; Xu, F.; Wang, H.; Zheng, Y. Effect of light on quality and bioactive compounds in postharvest broccoli florets. Food Chem. 2015, 172, 705-709. [CrossRef]

37. Zhang, S.; Zuo, L.; Zhang, J.; Chen, P.; Wang, J.; Yang, M. Transcriptome analysis of ulmus pumila 'jinye' responses to different shading involved in chlorophyll metabolism. Tree Genet. Genomes 2017, $13,64$. [CrossRef]

38. Kannangara, C.G.; Gough, S.P. Biosynthesis of $\Delta$-aminolevulinate in greening barley leaves: Glutamate 1-semialdehyde aminotransferase. Carlsberg Res. Commun. 1978, 43, 185-194. [CrossRef]

39. Tottey, S.; Block, M.A.; Allen, M.; Westergren, T.; Albrieux, C.; Scheller, H.; Merchant, S.; Jensen, P. Arabidopsis CHL27, located in both envelope and thylakoid membranes, is required for the synthesis of protochlorophyllide. Proc. Natl. Acad. Sci. USA 2003, 100, 16119-16124. [CrossRef]

40. Nagata, N.; Tanaka, R.; Tanaka, A. The major route for chlorophyll synthesis includes [3, 8-divinyl]-chlorophyllide a reduction in Arabidopsis thaliana. Plant Cell Physiol. 2007, 48, 1803-1808. [CrossRef]

41. Watson, G.W.; Beaver, L.M.; Williams, D.E.; Dashwood, R.H.; Ho, E. Phytochemicals from cruciferous vegetables, epigenetics, and prostate cancer prevention. AAPS J. 2013, 15, 951-961. [CrossRef] [PubMed]

42. Gigolashvili, T.; Yatusevich, R.; Berger, B.; Müller, C.; Flügge, U.-I. The R2R3-MYB transcription factor HAGL/MYB28 is a regulator of methionine-derived glucosinolate biosynthesis in arabidopsis thaliana. Plant J. 2007, 51, 247-261. [CrossRef] [PubMed]

43. Ménard, R.; Larue, J.P.; Silué, D.; Thouvenot, D. Glucosinolates in cauliflower as biochemical markers for resistance against downy mildew. Phytochemistry 1999, 52, 29-35. [CrossRef]

44. Mithen, R.F.; Lewis, B.G.; Fenwick, G.R. In vitro activity of glucosinolates and their products against leptosphaeria maculans. Fungal Biol. 1986, 87, 433-440. [CrossRef]

45. Mari, M.; Iori, R.; Leoni, O.; Marchi, A. In vitro activity of glucosinolate-derived isothiocyanates against postharvest fruit pathogens. Ann. Appl. Biol. 1993, 123, 155-164. [CrossRef]

46. Hanson, P.; Yang, R.Y.; Chang, L.C.; Ledesma, L.; Ledesma, D. Contents of carotenoids, ascorbic acid, minerals and total glucosinolates in leafy brassica pakchoi (Brassica rapa L. chinensis) as affected by season and variety. J. Sci. Food Agric. 2009, 89, 906-914. [CrossRef]

47. Steinbrecher, A.; Rohrmann, S.; Timofeeva, M.; Risch, A.; Jansen, E.; Linseisen, J. Dietary glucosinolate intake, polymorphisms in selected biotransformation enzymes, and risk of prostate cancer. Cancer Epidemiol. Biomark. Prev. 2010, 19, 135-143. [CrossRef]

48. Halkier, B.A.; Gershenzon, J. Biology and biochemistry of glucosinolates. Annu. Rev. Plant Biol. 2006, 57, 303-333. [CrossRef]

49. Kopsell, D.A.; Sams, C.E.; Morrow, R.C. Blue wavelengths from LED lighting increase nutritionally important metabolites in specialty crops. HortScience 2015, 50, 1285-1288. [CrossRef]

(C) 2020 by the authors. Licensee MDPI, Basel, Switzerland. This article is an open access article distributed under the terms and conditions of the Creative Commons Attribution (CC BY) license (http://creativecommons.org/licenses/by/4.0/). 